\title{
AVALIAÇÃO DA FILTRAÇÃO E OZONIZAÇÃO DE EFLUENTE SANITÁRIO PRIMÁRIO: ASPECTOS DE INATIVAÇÃO MICROBIANA E VARIÁVEIS DE OZONIZAÇÃO
}

\author{
Frederico de Almeida Lage Filho \\ Departamento de Engenharia Hidráulica e Sanitária, Escola Politécnica, Universidade de São Paulo. Av. Prof. Almeida Prado, \\ 83, 05508-900 São Paulo - SP, Brasil
}

Recebido em 6/3/07; aceito em 27/7/07; publicado na web em 26/2/08

\begin{abstract}
EVALUATION OF FILTRATION AND OZONATION OF A PRIMARY SANITARY EFFLUENT: ASPECTS OF MICROBIAL INACTIVATION AND OZONATION VARIABLES. Ozonation tests with and without prior filtration by means of a 50 micron mesh cartridge filter were conducted with primary sanitary effluents. Filtration led to increased inactivation efficiencies with regard to total and thermotolerant coliforms but it did not seem to influence heterotrophic plate count (HPC) bacteria inactivation efficiencies significantly. Application of the Chick-Watson model to experimental data obtained in the situation of constant inactivation showed that the ozone dosage was more important to bacterial inactivation than the contact time with regard to the cases of thermotolerant coliform inactivation in filtered samples and HPC bacteria and total coliform inactivation in non-filtered samples.
\end{abstract}

Keywords: primary sanitary effluent; filtration; ozonation.

\section{INTRODUÇÃO}

O Hospital Jacarepaguá na cidade do Rio de Janeiro, encaminha seus esgotos sanitários para tratamento em uma pequena estação localizada nas dependências do mesmo. Nesta estação é conduzida a seguinte seqüência de operações: tratamento preliminar, constituído pelas operações de gradeamento, remoção de óleos e graxas e caixa de areia, e tratamento primário por meio de um decantador para a remoção de sólidos suspensos. A direção do Hospital tenciona melhorar significativamente a qualidade microbiológica do efluente tratado e ficou interessada na possibilidade de implantação, na estação, de um processo de desinfecção do efluente por ozonização. Assim sendo, o Hospital autorizou a instalação de um sistema piloto constituído pelas operações de filtração em filtro de cartucho e ozonização em coluna de contato a ser operada em regime de batelada, para a execução de alguns ensaios de tratabilidade em caráter preliminar de avaliação.

$\mathrm{O}$ sistema piloto de tratamento instalado junto à estação de tratamento de esgotos sanitários do Hospital Jacareí permitiu avaliar em caráter preliminar a melhoria da qualidade microbiológica do efluente da estação de tratamento existente, a partir da avaliação de dois tipos de ensaios de tratabilidade: ozonização do efluente e filtração do efluente, seguida pela ozonização.

Deste modo, os objetivos dos ensaios de tratabilidade foram ${ }^{1}$ : avaliar o desempenho de cada tipo de ensaio de tratabilidade com o efluente da estação de tratamento existente, pela obtenção das eficiências de inativação de coliformes totais, coliformes termotolerantes e bactérias heterotróficas; avaliar a importância relativa de duas variáveis de ozonização no tocante às eficiências de inativação supracitadas: o tempo de contato do ozônio no efluente e a massa de ozônio transferida ao efluente por unidade de tempo de contato.

\section{PARTE EXPERIMENTAL}

Foi utilizada como reator de aplicação de ozônio uma coluna

*e-mail: fredlage@usp.br cilíndrica feita de acrílico rígido. A Figura 1 mostra a coluna de ozonização, com 1,70 m de altura útil e diâmetro interno de $10 \mathrm{~cm}$, tendo na base um difusor poroso de formato cilíndrico para a introdução de gás ozônio. O gerador aparece ao lado da coluna na Figura 1. O gás de geração de ozônio foi oxigênio puro e o gerador (da Trailigaz, Inc.) possuía capacidade nominal de $20 \mathrm{~g} \mathrm{O}_{3} / \mathrm{h}$. Um sistema de monitoria acoplado ao sistema de ozonização permitia registrar a massa de ozônio transferida para a fase líquida por unidade de volume, a partir da determinação da diferença entre a massa de ozônio aplicada (aproximadamente constante, na faixa de 2,1 a 2,2 $\mathrm{mg} \mathrm{O}_{3} / \mathrm{L}$ por minuto de contato) e a massa de ozônio que saía pelo topo da coluna pelo tubo de "off gas". Desse modo, era determinada a massa de ozônio transferida para a fase líquida e o tempo de contato correspondente, em cada ensaio de tratabilidade.

Para os ensaios de tratabilidade com filtração do efluente sanitário hospitalar previamente à ozonização, foi utilizado um filtro de cartucho marca Cuno, com cartuchos com malha de 50 micras, com a colocação de cartuchos novos antes de cada ensaio de tratabilidade.

\section{RESULTADOS E DISCUSSÃO}

\section{Características do efluente sanitário antes e após a filtração}

A Tabela 1 mostra algumas características médias do efluente sanitário antes e após a filtração. Todas as determinações foram feitas em triplicata. As análises de sólidos suspensos totais (SST) e da demanda química de oxigênio (DQO) foram executadas de acordo a metodologia expressa no "Standard Methods for the Examination of Water and Wastewater" 2 . As contagens de coliformes totais e termotolerantes foram obtidas, a partir da utilização de "kits" portáteis de contagem Colilert (Sovering do Brasil). As contagens de bactérias heterotróficas, feitas em termos de placas heterotróficas, foram obtidas a partir da cultura das amostras dos efluentes da estação de tratamento e do tratamento piloto em agar padrão, conforme o procedimento detalhado pelo "Standard Methods"'. A temperatura do efluente sanitário foi de $22{ }^{\circ} \mathrm{C}$ durante a execução de todos os ensaios de tratabilidade. $\mathrm{O}$ pH do efluente sanitário antes 


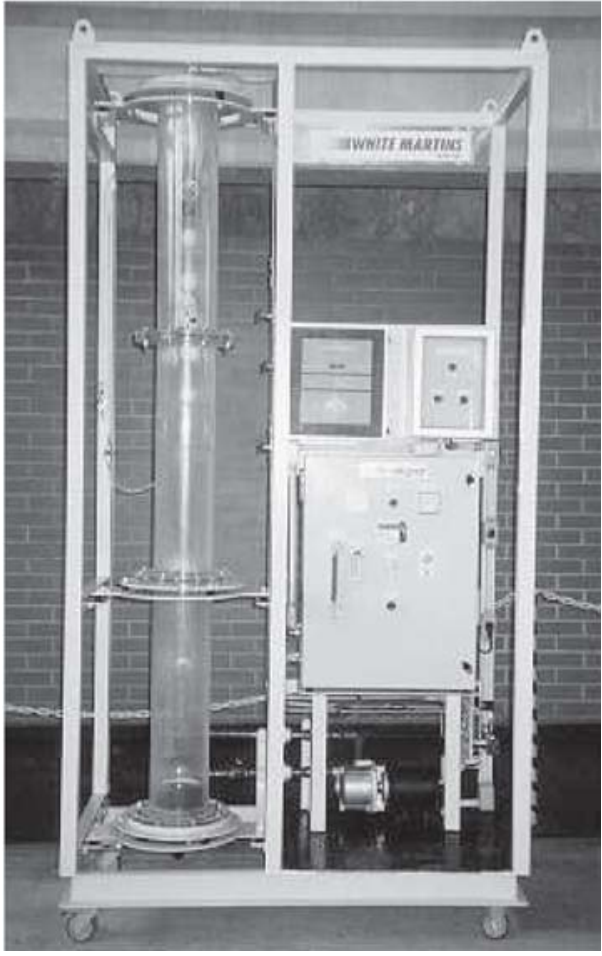

Figura 1. Sistema de ozonização em escala piloto

e após a filtração em cartucho foi 7,5. De acordo com Bitton ${ }^{3}$, a eficácia do ozônio como desinfetante não é controlada pelo $\mathrm{pH}$.

De acordo com os resultados apresentados na Tabela 1, a filtração em cartucho reduziu o valor médio de DQO do efluente em $13,3 \%$, um valor relativamente baixo. Analogamente, a filtração em cartucho reduziu o valor médio da concentração de sólidos suspensos totais em cerca de $12,8 \%$, um valor relativamente baixo. De acordo com os resultados obtidos por Janex et al. ${ }^{4}$ em experimentos em escala piloto de desinfecção de esgoto sanitário com ozônio, o conteúdo de matéria orgânica no esgoto, expresso como demanda química de oxigênio (DQO) e carbono orgânico total (COT), foi a variável que mais influenciou o consumo de ozônio pelo esgoto sanitário. Assim sendo, a influência da filtração em cartucho sobre o consumo de ozônio devido à DQO e aos teores de sólidos suspensos das amostras deve ter sido relativamente pequena. De acordo com Langlais et al. ${ }^{5}$, as principais características físicas e químicas a influenciar a desinfecção por ozônio são: temperatura, turbidez, COT e $\mathrm{pH}$, sendo que a turbidez está diretamente relacionada ao teor de sólidos suspensos. Temperaturas relativamente baixas da fase líquida (como referência, abaixo de $15{ }^{\circ} \mathrm{C}$ ) são prejudiciais à eficácia do ozônio como desinfetante. Aumentos de temperatura aceleram a velocidade de decomposição do ozônio e pH do líquido acima de 7 também acelera a decomposição do ozônio, em vista do predomínio de íons hidróxido $\left(\mathrm{OH}^{-}\right)$sobre os ions hidrogênio $\mathrm{H}^{+}$. De acordo com o que foi informado anteriormente sobre as condições dos ensaios de tratabilidade, a temperatura do efluente durante os ensaios foi constante e com valor de 22 ${ }^{\circ} \mathrm{C}$, e o $\mathrm{pH}$ foi constante e com valor 7,5. Desde modo, podemos descartar a influência de variações de temperatura e de $\mathrm{pH}$ do efluente no consumo de ozônio durante os ensaios. Com relação à variável turbidez, a quebra de sólidos pela filtração pode explicar o aumento da turbidez (cerca de $8 \%$ ) em relação ao efluente primário não-filtrado. A área específica de partículas (relação área/volume) aumenta com a diminuição do tamanho das mesmas, então é provável que o grau de proteção proporcionada aos microrganismos pelas partículas sólidas tenha aumentado com a filtração.
Inativação de bactérias heterotróficas, coliformes totais e coliformes termotolerantes

As Tabelas 2 e 3 mostram os valores das variáveis de ozonização observados durante os ensaios de tratabilidade e as eficiências de inativação de bactérias heterotróficas, coliformes totais e coliformes termotolerantes. A Tabela 2 refere-se aos ensaios de ozonização de efluente sanitário não-filtrado e a Tabela 3 , aos ensaios com efluente sanitário filtrado e ozonizado. Com os valores de eficiências de inativação, foram construídos gráficos mostrando as frações de microrganismos não-inativados remanescentes em função do tempo de contato de ozonização.

As Figuras 2 a 4 mostram os resultados de inativação microbiana em escala logarítmica, em termos de fração de bactérias remanescentes após desinfecção: "N" bactérias remanescentes divididas por "No" ou contagem inicial de bactérias. A Figura 2 refere-se às contagens de placas heterotróficas, a Figura 3 às concentrações de coliformes totais e a Figura 4 às concentrações de coliformes termotolerantes. As curvas de melhor ajuste aos dados experimentais, com suas respectivas equações e coeficientes de correlação $\left(\mathrm{R}^{2}\right)$ estão indicadas em cada Figura. Conforme explicado anteriormente, a transferência de ozônio para a fase líquida foi controlada e aproximadamente constante, na faixa de 2,1 a 2,2 mg/L por minuto de tempo de contato de ozonização, durante todos os ensaios.

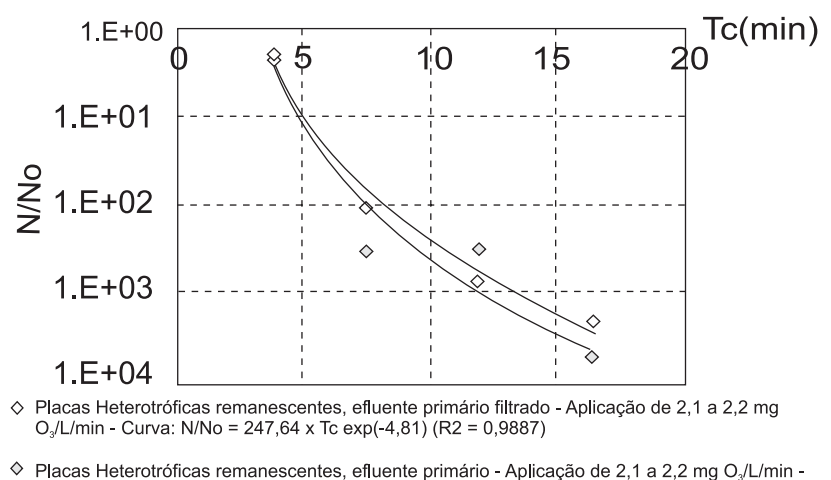

$\diamond$ Placas Heterotróficas remanescentes, efluente primário - Aplicação de 2,1 a 2,2 mg $\mathrm{O}_{3} / \mathrm{L} / \mathrm{min}$ Curva: $\mathrm{N} / \mathrm{No}=413,45 \times \mathrm{Tc} \exp (-5,18)(\mathrm{R} 2=0,9201)$

Figura 2. Inativação de bactérias heterotróficas

Com relação à inativação de bactérias heterotróficas, a Figura 2 mostra que houve uma diferença relativamente pequena entre os resultados de inativação para efluente filtrado e não-filtrado. Para uma determinada eficiência de inativação de bactérias heterotróficas, o tempo de contato necessário para o efluente pré-filtrado foi ligeiramente maior ( 1 min a mais, no máximo) que o tempo de contato necessário para o efluente primário não-filtrado.

Com relação à inativação de coliformes totais, a Figura 3 mostra que, para uma determinada eficiência de inativação, o tempo de contato necessário para o efluente não-filtrado foi significativamente maior (cerca de 2 a 3 min maior) que o tempo de contato necessário para o efluente pré-filtrado.

Com relação à inativação de coliformes termotolerantes, a Figura 4 mostra que, para uma determinada eficiência de inativação, o tempo de contato necessário para o efluente não-filtrado foi significativamente maior (alguns minutos a mais) que o tempo de contato necessário para o efluente pré-filtrado.

Para um tempo de contato de 15 min na ozonização de efluente sanitário primário (esgoto doméstico após tratamento preliminar e sedimentação primária, como neste trabalho), Metcalf e Eddy ${ }^{6}$ indicaram uma dosagem de ozônio na faixa de 10 a $40 \mathrm{mg} / \mathrm{L}$ como necessária para a redução da concentração de coliformes totais na 
Tabela 1. Características do efluente sanitário utilizado nos ensaios: valores médios (para $\mathrm{n}=3$ amostras de efluente da estação de tratamento)

\begin{tabular}{lccccccc}
\hline Efluente sanitário & $\begin{array}{c}\text { DQO } \\
(\mathrm{mg} / \mathrm{L})\end{array}$ & $\begin{array}{c}\mathrm{SST} \\
(\mathrm{mg} / \mathrm{L})\end{array}$ & $\begin{array}{c}\text { Turbidez } \\
(\mathrm{NTU})\end{array}$ & $\begin{array}{c}\mathrm{pH} \\
(-)\end{array}$ & $\begin{array}{c}\text { Placas } \\
\text { heterotróficas } \\
(\mathrm{n} . / 100 \mathrm{~mL})\end{array}$ & $\begin{array}{c}\text { Coliformes tot. } \\
(\mathrm{NMP} / 100 \mathrm{~mL})\end{array}$ & $\begin{array}{c}\text { Coliformes termo } \\
\text { tolerantes } \\
(\mathrm{NMP} / 100 \mathrm{~mL})\end{array}$ \\
\hline Sem filtração & 300,0 & $44, .3$ & 27,1 & 7,5 & $8,4 \times 10^{6}$ & $2,2 \times 10^{6}$ & $1,4 \times 10^{6}$ \\
$\begin{array}{l}\text { Filtrado, antes } \\
\text { da ozonização }\end{array}$ & 260,0 & 37,6 & 29,2 & 7,5 & $1,1 \times 10^{9}$ & $1,1 \times 10^{9}$ & $1,0 \times 10^{7}$ \\
\hline
\end{tabular}

OBS.: DQO = Demanda Química de Oxigênio. SST = Sólidos Suspensos Totais.

Tabela 2. Resultados dos ensaios de ozonização com efluente primário não-filtrado

\begin{tabular}{lcccccc}
\hline Ensaio & $\begin{array}{c}\text { Consumo } \\
\text { de } \mathrm{O}_{3}\end{array}$ & $\begin{array}{c}\text { T contato } \\
(\mathrm{min})\end{array}$ & $\begin{array}{c}\text { Consumo tot. } \\
\text { de } \mathrm{O}_{3} \\
\text { no ensaio }(\mathrm{mg} / \mathrm{L})\end{array}$ & Heterotróficas & $\begin{array}{c}\text { Eficiências de inativação (\%) } \\
\text { Colif. } \\
\text { Tot. }\end{array}$ & $\begin{array}{c}\text { Colif. } \\
\text { Termotol. }\end{array}$ \\
\hline 1 & 2,25 & 4 & 9,0 & 53,57 & 99,73 & 99,09 \\
2 & 2,25 & 8 & 18,0 & 99,74 & 99,85 & 99,21 \\
3 & 2,12 & 12 & 25,5 & 99,72 & 99,99 & 99,94 \\
4 & 2,01 & 16 & 32,2 & 99,98 & 99,99 & 99,99 \\
\hline
\end{tabular}

Tabela 3. Resultados dos ensaios de ozonização com efluente primário filtrado

\begin{tabular}{lcccccc}
\hline Ensaio & $\begin{array}{c}\text { Consumo } \\
\text { de } \mathrm{O}_{3}\end{array}$ & $\begin{array}{c}\text { T contato } \\
(\mathrm{min})\end{array}$ & $\begin{array}{c}\text { Consumo tot. } \\
\text { de } \mathrm{O}_{3} \\
\text { ng/L x min) }\end{array}$ & & Hensaio $(\mathrm{mg} / \mathrm{L})$ & \multicolumn{2}{c}{$\begin{array}{c}\text { Eficiências de inativação (\%) } \\
\text { Colif. } \\
\text { Tot. }\end{array}$} & $\begin{array}{c}\text { Colif. } \\
\text { Termotol. }\end{array}$ \\
\hline 1 & 2,12 & 4 & 8,5 & 61,45 & 67,86 & 68,57 \\
2 & 2,19 & 8 & 17,5 & 99,20 & 99,75 & 99,43 \\
3 & 2,15 & 12 & 25,8 & 99,87 & 99,92 & 99,70 \\
4 & 1,98 & 16 & 31,6 & 99,95 & 99,99 & 99,71 \\
\hline
\end{tabular}

faixa de $10^{7}$ a $10^{9} \mathrm{NMP} / 100 \mathrm{~mL}$ para $10^{3} \mathrm{NMP} / 100 \mathrm{~mL}$, o que equivale à obtenção de uma fração de coliformes remanescentes $\mathrm{N} /$ No na faixa de $10^{-4}$ a $10^{-6}$. Em nossa investigação, para a obtenção de uma fração de coliformes remanescentes N/No de cerca de $10^{-4}$ para o efluente filtrado assim como para o efluente não-filtrado, para o referido tempo de contato de $15 \mathrm{~min}$, foi necessária uma dose de ozônio de cerca de $32 \mathrm{mg} / \mathrm{L}$, portanto, dentro da faixa de dosagem supramencionada.

Gonçalves ${ }^{7}$ relatou experimentos de ozonização em escala piloto conduzidos com efluentes secundários de uma estação de tratamento do tipo lodo ativado, ou seja, com efluentes do decantador secundário da estação. A concentração do coliforme indicador $E$. coli era de $10^{5} \mathrm{NMP} / 100 \mathrm{~mL}$ no efluente secundário. Característi-

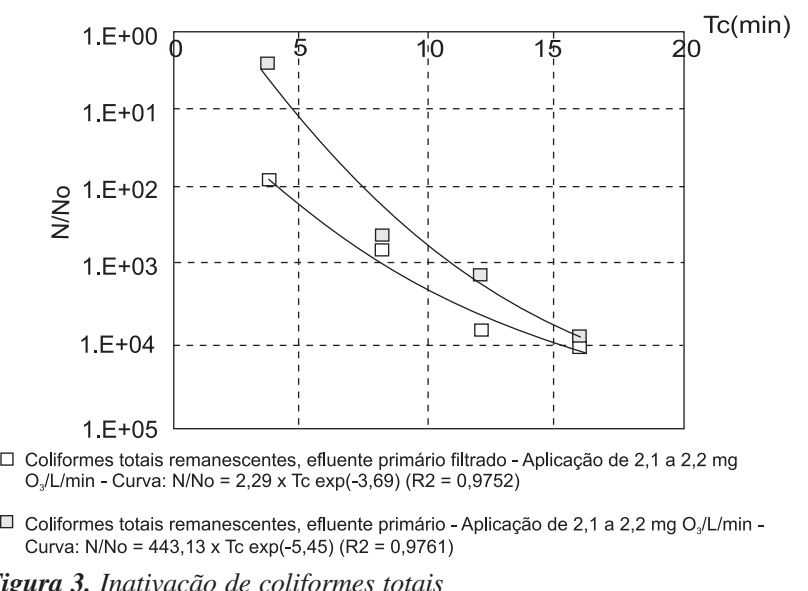

Figura 3. Inativação de coliformes totais cas físico-químicas deste efluente não foram informadas. Foi utilizado um gerador de ozônio com capacidade de geração de $20 \mathrm{~g} \mathrm{O}_{3} /$ h e uma câmara de contato de $15 \mathrm{~L}$ de volume, operada em regime de batelada. Um tempo de contato de 2,5 min e uma dosagem de $12 \mathrm{mg} / \mathrm{L}$ levaram a uma redução da concentração de E. coli de $10^{5}$ para $10^{3} \mathrm{NMP} / 100 \mathrm{~mL}$. Em outra investigação descrita por Gonçalves ${ }^{7}$, ozônio foi aplicado a um efluente de um sistema de tratamento formado por uma lagoa anaeróbia seguida por uma lagoa facultativa em série. O efluente da lagoa facultativa apresentou DBO na faixa de 60 a $90 \mathrm{mg} / \mathrm{L}$ e sólidos totais na faixa de 50 a $60 \mathrm{mg} / \mathrm{L}$. Ozônio foi gerado a partir do ar ambiente e o gerador aplicou 110 $\mathrm{mg} \mathrm{O}_{3} / \mathrm{min}$ na fase líquida. As concentrações de ozônio no líquido variaram de 1,9 a 9,6 mg/L e o tempo de contato na coluna de

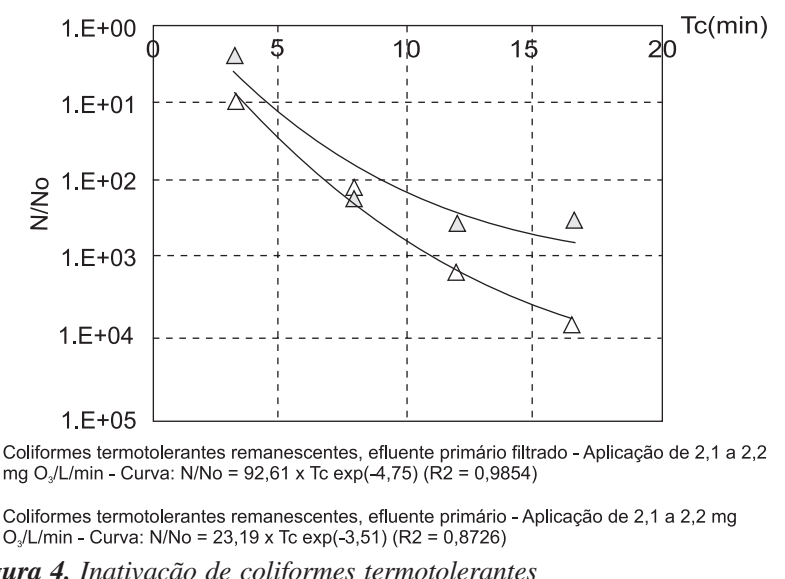


ozonização de $171 \mathrm{~L}$ e operada em regime de batelada variou de 2,9 a $15 \mathrm{~min}$. As concentrações de $E$. coli estiveram sempre acima de $10^{5} \mathrm{NMP} / 100 \mathrm{~mL}$, e a eficiência de inativação foi tipicamente de um log ou $90 \%$. Também foi relatado que a eficiência média de inativação de colifagos foi de $90 \%$.

\section{Avaliação econômica da ozonização de efluentes sanitários}

Bassani $^{8}$ obteve equações baseadas em dados experimentais para estimativa de diversos tipos de custos unitários referentes a sistemas de ozonização de efluentes domésticos. As hipóteses adotadas pelo autor foram: aplicação de $4 \mathrm{~g} \mathrm{O}_{3} / \mathrm{m}^{3}$ de efluente; geração de $160 \mathrm{~L}$ de efluente por habitante e por dia. Os custos com energia consideraram custo de $\mathrm{R} \$ 0,25$ por $\mathrm{kWh}$ e a necessidade de 9,7 $\mathrm{kWh}$ por $\mathrm{kg}$ de $\mathrm{O}_{3}$ gerado. Os custos com oxigênio de geração foram estimados considerando custo de $\mathrm{R} \$ 1,50$ por $\mathrm{m}^{3} \mathrm{e}$ a produção de $4 \mathrm{~g} \mathrm{O}_{3} / \mathrm{m}^{3}$ de gás. $\mathrm{O}$ autor considerou ainda populações atendidas na faixa de 10.000 a 250.000 habitantes e o fator de 3,75 habitantes por economia. Fatores de conversão de câmbio utilizados foram: $\mathrm{R} \$ 3,60$ por US $\$ 1,00$ e 0,88 Euros por US $\$ 1,00$. As seguintes equações de custos foram obtidas:

produção de ozônio a partir de oxigênio puro e ar, em função da capacidade de geração:

Custo $\left(\mathrm{R} \$ / \mathrm{kg} \mathrm{O}_{3}\right.$ x mês $)=8099 \times\left(\mathrm{kg} \mathrm{O}_{3} / \text { mês }\right)^{-0,2957}$ para geração a partir de ar, com coeficiente de correlação $\mathrm{R}^{2}=0,97$.

Custo $\left(\mathrm{R} \$ / \mathrm{kg} \mathrm{O}_{3}\right.$ x mês $)=6503 \times\left(\mathrm{kg} \mathrm{O}_{3} / \mathrm{mês}^{-0,3672}\right.$ para geração a partir de oxigênio, com coeficiente de correlação $R^{2}=0,88$.

Para os tipos seguintes de custos, foi considerada apenas a geração de ozônio a partir de oxigênio, "por ser muito mais econômico que o sistema de geração a partir do ar" (Bassini ${ }^{8}$, apud Gonçalves $^{7}$ ).

Custos com oxigênio:

Custo $(\mathrm{R} \$ / \mathrm{mês})=1,5 \times(0,2222 \times \mathrm{n}$. de habitantes $)$, para populações na faixa 10.000 a 50.000 habitantes.

Custo $(\mathrm{R} \$ / \mathrm{mês})=1,5 \times(0,1333 \times \mathrm{n}$. de habitantes $)$, para populações na faixa 100.000 a 250.000 habitantes.

Custos de manutenção:

Estimados como sendo $15 \%$ da soma dos custos com oxigênio e com energia elétrica.

Custos operacionais totais:

Considerando a soma dos custos devidos ao consumo de oxigênio, de energia e de manutenção, Bassini ${ }^{8}$ apud Gonçalves ${ }^{7}$ obteve os valores:

$\mathrm{R} \$ 1,64 /$ mês x economia para populações na faixa de 10.000 a 50.000 habitantes;

$\mathrm{R} \$ 1,06 /$ mês $\mathrm{x}$ economia para populações na faixa de 100.000 a 250.000 habitantes.

Custos de implantação de sistemas de ozônio, por habitante: Custo por habitante: $(\mathrm{R} \$)=533,6 \times$ (n. de habitantes) $)^{-0,3673}$, com $\mathrm{R}^{2}$ $=1,00$.

Custos de construção:

Segundo Gonçalves ${ }^{7}$, "os custos de construção são fortemente dependentes das condições locais; além disso, o valor é baixo quando comparado a outros componentes de custo". Essa componente de custos não foi avaliada pelo autor.

De fato, normalmente o local de aplicação influencia significativamente os componentes de custos associados a sistemas de ozonização. Além disso, uma vez que a concentração de ozônio gerada é baixa, sendo típicamente na faixa de 2 a $6 \%$ por peso em relação ao gás de geração, pode-se afirmar que a eficiência de transferência de ozônio para a fase líquida do efluente é uma consideração econômica muito relevante para sistemas de ozonização.

\section{Importância relativa da dose de ozônio e do tempo de contato}

A lei de Chick-Watson de inativação bacteriana pode ser expressa pela equação:

$\mathrm{dN} / \mathrm{dt}=-\mathrm{k}^{\prime} \times \mathrm{N}$

onde k' é uma constante. A integração de (1) resulta em:

$\ln \mathrm{N} / \mathrm{No}=-\mathrm{k}^{\prime} \mathrm{x} \mathrm{t}$

onde ln representa logaritmo Neperiano (base e) e N/No é a fração de bactérias sobreviventes após o tempo de contato t. Posteriormente ficou estabelecido que k' podia ser expresso por:

$\mathrm{k}^{\prime}=\mathrm{k}^{\prime \prime} \mathrm{x} \mathrm{C}^{\mathrm{n}}$

onde n e k" são constantes.

$\mathrm{O}$ valor do expoente $\underline{\mathrm{n}}$ pode ser determinado experimentalmente em certos casos. Se o valor de $\underline{\mathrm{n}}$ for maior que a unidade, então a importância relativa da dosagem de desinfetante para a desinfecção é maior que a do tempo de contato; o contrário é válido se o valor obtido para $\underline{n}$ for menor que a unidade. De acordo com Tchobanoglous et al. ${ }^{9}$, a Lei de Chick-Watson é válida para cloro, dióxido de cloro e ozônio.

Masschelein ${ }^{10}$ afirmou que "fundamentalmente, o conceito de $\mathrm{C}$ e $\mathrm{T}$ (sendo $\mathrm{C}$ a concentração de desinfetante na fase líquida e $\mathrm{T}$ o tempo de contato) não parece ser aplicável sem restrições à desinfecção de líquidos com ozônio e outros desinfetantes, e isto é devido a várias razões fundamentais" (variabilidade da concentração do desinfetante, consumo competitivo de ozônio por compostos químicos no líquido, auto-decomposição do ozônio, mecanismos associados à ocorrência de um "lag" ou tempo de retardo ligado à desinfecção, e outros fatores). $\mathrm{O}$ autor recomendou cautela mas não desmereceu o modelo de Chick-Watson de inativação, que foi aplicado a valores experimentais obtidos nesse trabalho com o intuito de avaliar a importância relativa da dosagem de ozônio e do tempo de contato, sem no entanto avaliar o mérito da argumentação de Masschelein ${ }^{10}$ com relação à predição da eficiência de inativação bacteriana.

Para uma eficiência de inativação (representada pela relação N/No) constante, e combinando as Equações 2 e 3, tem-se:

$\mathrm{C}^{-\mathrm{n}}=-\mathrm{Kxt}$

onde K é uma constante, igual a k"/ ln (N/No). A linearização de (4) resulta na equação da reta:

$\mathrm{n} x \ln \mathrm{C}=\ln \mathrm{K}+\ln \mathrm{t}$

onde "n" é a tangente do ângulo formado pela reta com uma linha horizontal.

A Figura 5 apresenta o gráfico obtido a partir de seis pares de dados de dosagem de ozônio e tempo de contato correspondente, obtidos das Tabelas 2 e 3. Esses pares de dados se referem a uma condição de eficiência de inativação (N/No) de 99,71 a 99,99, que pode ser considerada aproximadamente constante. A rigor, as efici- 


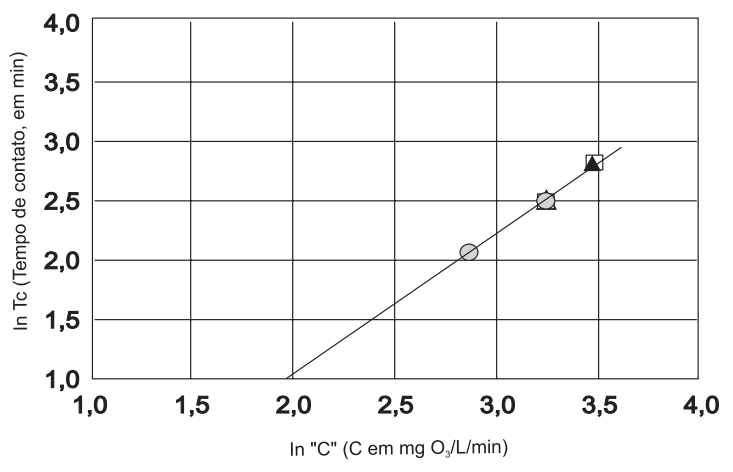

口 99,99\% de remoção de coliformes, totais - efluente primário

\99,7\% de remoção de coliformes termotolerantes - efluente primário filtrado O 99,73\% de remoção de heterotróficas - efluente primário. OBS: : Equação da reta para todos os
pontos: $\operatorname{Ln} T \mathrm{Tc}=1,214(\ln \mathrm{C})-1,444(\mathrm{R} 2=0,995)$.

Figura 5. Aplicação do modelo de inativação de Chick - Watson e importância relativa da concentração " $C$ " de ozônio na fase líquida e do tempo de contato "Tc"

ências de inativação obtidas foram: 99,73\% para bactérias heterotróficas (oriundas dos ensaios com efluente não-filtrado), $99,99 \%$ para coliformes totais (oriundas dos ensaios com efluente não-filtrado) e 99,71\% para coliformes termotolerantes (oriundas dos ensaios com efluente filtrado). Os seis pares de dados apresentaram ótimo alinhamento, que resultou em uma única curva de melhor ajuste dos pontos.

O coeficiente de correlação obtido para a curva de melhor ajuste foi $\mathrm{R}^{2}=0,995$. O coeficiente angular obtido da equação da reta (n) foi de aproximadamente 1,2, sendo maior que a unidade. De acordo com as considerações expostas anteriormente, pode-se inferir que a importância relativa da dose de ozônio dissolvida foi maior que a do tempo de contato no tocante à inativação bacteriana, nos casos de dados experimentais que resultaram em eficiência de inativação aproximadamente constante.

\section{CONCLUSÕES}

A filtração do efluente pareceu não influenciar significativamente a eficiência de inativação de bactérias heterotróficas. As eficiências de inativação de coliformes termotolerantes e de coliformes totais em efluente filtrado foram maiores que no caso de efluente não-filtrado. No caso dos coliformes termotolerantes, quanto maior o tempo de contato, maior a diferença entre as eficiências de inativação de efluente filtrado e não-filtrado. No caso dos coliformes totais, um aumento do tempo de contato não significou aumento da diferença entre as eficiências de inativação de efluente filtrado e não-filtrado. A aplicação do modelo de Chick-Watson sob a condição de eficiência de inativação aproximadamente constante (nos casos de inativação de heterotróficas em efluente não-filtrado, de inativação de coliformes termotolerantes em efluente filtrado e de inativação de coliformes totais em efluente não-filtrado) mostrou que a dose de ozônio transferida para a fase líquida teve maior importância na inativação bacteriana que o tempo de contato.

\section{REFERÊNCIAS}

1. Lage Filho, F. A.; Relatório CTR, Grupo de águas e efluentes da White Martins, 2003

2. WEF/AWWA/APHA; Standard Methods for the Examination of Water and Wastewater, $18^{\mathrm{a}}$ ed., 1996.

3. Bitton, G.; Wastewater Microbiology, $1^{\text {rst }}$ ed., Wiley: New York, 1994.

4. Janex, M. L.; Savoye, P.; Roustan, M.; Do-Quang, Z.; Lainé, J. M.; Lazarova, V.; Ozone: Sci Eng. 2000, 22, 113.

5. Langlais, B. Em Ozone in Water Treatment: Application \& Engineering; Langlais, B.; Reckhow, D. A; Brink, D. R., eds.; $1^{\text {st }}$ ed., Lewis Publishers,: Boca Raton, 1991.

6. Metcalf \& Eddy, Inc.; Wastewater Engineering: Treatment and Reuse, $4^{\text {th }}$ ed., McGraw-Hill: New York, 2003.

7. Gonçalves, R. F. Em Desinfecção de Efluentes Sanitários. PROSAB, Edital III, 2003.

8. Bassani, L.; Dissertação de Mestrado, Universidade Federal de Santa Catarina, Brasil, 2003.

9. Tchobanoglous, G; Schroeder, E. D.; Water Quality: Characteristics, Modeling, Modification, $1^{\text {st }}$ ed. , Addison-Wesley: Massachusetts, 1987.

10. Masschelein, W. J.; Ozone: Sci. Eng. 2000, 22, 227. 